\title{
Moving towards 2020: A Tentative Approach to ITEM
}

\author{
Javier Osorio and Jacques Bulchand \\ Universidad de Las Palmas de Gran Canaria, \\ Facultad de Ciencias Economicas, \\ 35017 Las Palmas de Gran Canaria, Spain \\ josorio@dede.ulpgc.es
}

\begin{abstract}
A decade into the 21 st Century, it seems that Humanity has given itself time to ensure that the rest of the century will pass by according to the universally accepted principles of equal opportunities and sustainable economic development. Year 2020 appears as a symbolic moment to attain this desired maturity, though it is, nevertheless, a complex goal to reach. Education is an essential area in any action that intends to accomplish this model of society, an instrument without which all efforts will be in vain. The outline of this paper is to try to glimpse which will probably be the determining factors of the worldwide economic situation and, therefore, what kind of professionals society will be demanding. The reply to this demand will structure future teaching and learning, and a series of needs will subsequently arise in Educational Management. Finally, according to this scenario we will propose improvements in Educational Management supported by Information Technology.
\end{abstract}

Keywords: Learning 2.0, Web 2.0, Education \& Training, Information Technology, 2020, ITEM.

\section{Introduction}

Year 2020 has become an especially relevant date in which to accomplish certain indicators regarding climate change prevention and more environmentally aware lifestyles. The Copenhagen Climate Change Summit 2009 has been an important milestone that has contributed to reinforce 2020's iconic symbolism. Also, the United Nations Millennium Goals are another milestone to achieve. But 2020 is not only a key date to check if these internationally shared aspirations concerning the environment and society have been completed, but also a crucial date as regards education. Will we be ready by then to state that citizens are being offered an education that responds to the times? Moreover, we could include this query in the subsequent debate as to whether integrating people into a national education system to provide them with skills and competences, as well as accrediting their achievement, will make sense in 2020.

If we accept that an education system's aim is to train citizens and professional persons to carry out their work in such a way as to allow both individuals and

A. Tatnall, O.C. Kereteletswe, and A. Visscher (Eds.): ITEM 2010, IFIP AICT 348, pp. 104-112, 2011. (C) IFIP International Federation for Information Processing 2011 
communities to benefit from the knowledge and competences so acquired, then we should firstly establish which could be the future working environment's main characteristics in a hypothetical scenario, setting year 2020 as a time reference.

Starting off from here we could then consider which should be the education system's goals for its different levels. After that the next step could be to deduce possible trends in education. At this point we could centre our attention on our specific interest, that is to say, establishing Information Technologies' role in Educational Management and, subsequently, what actions are required to ensure that Information Technologies effectively contribute to improve Educational Management. Figure 1 shows part of the aspects we have mentioned as well as the outline of this paper.

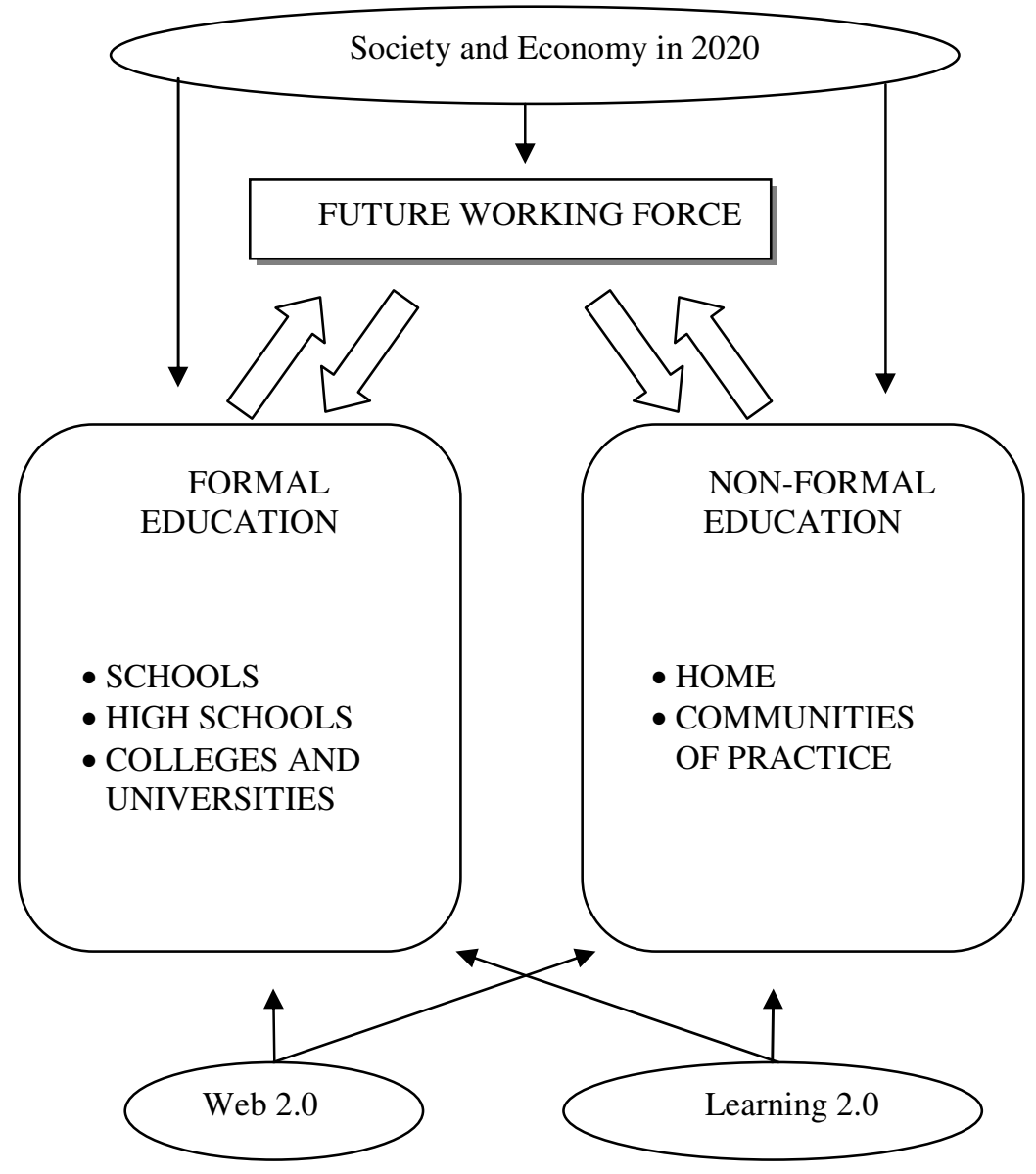

Fig. 1. Interrelated Challenges for Educational Management 


\section{Trends Regarding Skills and Competences Required by the Labour Market}

The European Qualification Framework ${ }^{1}$ gives a precise definition for the terms "skills" and "competences" in order to establish a common working language. According to these recommendations, skills means the ability to apply knowledge and use know-how to complete tasks and solve problems. In the context of the European Qualification Framework, skills are described as cognitive (involving the use of logical, intuitive and creative thinking) and practical (involving manual dexterity and the use of methods, materials, tools and instruments). On the other hand, competence means the proven ability to use knowledge, skills and personal, social and/or methodological abilities, in work or study situations and in professional and personal development. In the context of the European Qualification Framework, competence is described in terms of responsibility and autonomy.

These two basic concepts have become important in the European and international educational picture as a form of agreement on a common language that will allow setting goals and indicators of their achievement, notwithstanding the educational level, whether it be primary, secondary or higher education. Having ascertained these basic concepts, we can now consider aspects that will influence education in our set time reference, such as the labour market. This will allow us to identify the challenges Educational Management will be facing and, more specifically, the challenges to ensure an optimal use of information technologies to support Educational Management.

\section{Anticipating and Adjusting the Labour Market and Necessary Skills}

It's impossible to say for certain what the future holds in 2020 as regards labour matters, just as impossible as trying to predict our own future in any area of our lives. Nevertheless, it is generally agreed that we must try to anticipate and plan for the future in order to avoid undesirable results and, to the contrary, make the most of any opportunities that may arise. In the socioeconomic field, attempting to predict and plan is a strategic activity, due to the implications it has for the market and labour policies. In a wide sense, education is very sensitive to the labour market needs. Certainly, formal education of children, young people and adults cannot depend exclusively on such demands, as they are of a contextual nature, but it is also true that students are trained to carry out their professional activity under specific socioeconomic conditions and they must be fully qualified to offer their best in a defined professional environment.

Therefore, as previously mentioned, and although not a conclusive element, anticipating what the labour environment will be like towards 2020 can give us important clues as to some of the main aspects on which to build educational structures and systems that will provide students with skills and competences that will respond adequately to the labour challenges of the future. Consequently, we should

\footnotetext{
${ }^{1}$ Recommendation of the European Parliament and the Council (2008) on the establishment of the European Qualifications Framework.
} 
try at an early stage to identify the skills and competences required. Accordingly, we must also discover factors that may condition the future labour market and, as a result, the educational system. Some of these are as follows:

Technological change. Technological change is part of an equation in which the need for skilled workers is directly proportional to the magnitude of change required. In fact, technological change is considered the main reason stated to justify the need for highly skilled workers (Machin and Van Reenen, 2007).

Organizational change. Parallel to technological development, ways of organizing work evolve according to such varied criteria as the search for flexible production systems, product and service customization, quality improvement, production chain optimization, humanization of work, etc. All of them are usually associated with a body of knowledge that subsequently demands skilled workers who are capable of adapting to new situations (Breshanan et al., 2002).

Globalization and international commerce. Over the past years we have witnessed an increase of international commerce without precedent in the World's economic history. Traditionally developed countries, which are specialized in turning out high added value products and services, have centred the demand for skilled workers, whereas emerging countries, with a less skilled workforce, have concentrated on a low added value production. Nevertheless, similarly to what happened in Japan during the 70's, the current trend is for developing countries to focus increasingly on generating high added value products and services and, therefore, they need to train more highly skilled students. Following the action-reaction mechanism, if developed countries want to continue being competitive, they will have to make a decided bet for innovation and superspecialization, which in turn requires developing more skills and competences.

Climate change and environmental challenges. Over the last few years both governments and citizens have become increasingly aware of the damage economy can suffer due to climate change. This has brought around a general effort to reduce climate change and combat environment degradation, a trend that could favour the surge of a green economy that would employ millions of skilled workers all over the world (UNEP, 2008).

All these factors are currently foremost, but will probably have taken second place as we approach 2020, when new circumstances and concerns will dominate the economic, social and, therefore, educational scenario. This does not mean we should ignore such factors, quite to the contrary it would be convenient to consider them a starting point to begin to plan for the future, though allowing for new variables as they appear.

In short, we can refer to the document published by the European Commission \{COM(2008)868\}, titled New Skills for New Jobs: Anticipating and matching labour market and skill needs, which explains that socioeconomic changes imply the need for more highly skilled workers with an increased capacity to add value through their work and, therefore, a greater demand of university graduates, the education level that will experiment the greatest growth. In this sense, the REFLEX report (ANECA, 2008) states that university graduates of the future will have to be competent in at least the following five areas: professional expertise, functional flexibility, innovation and knowledge management, mobilisation of human resources, and international orientation. 
Although we don't want to study these aspects more in depth, and continuing with this paper's basic argument as put forward in the introduction, we would like to try to perceive the implications of socioeconomic trends for the education system as respects the skills and competences of future professionals, considering all educational levels and not just the university one.

\section{Educational Institutions on the Horizon of 2020}

As mentioned above, as a result of a series of circumstances towards 2020 the socioeconomic setting will point towards the need for graduates with highly specialized skills and competences, mainly because that society will no longer be dominated by the industrial era's logic based on mass production and mass consumption. Foreseeably, large scale production will cease to be the main guideline and will give way to the creation of added value, mostly at an individual level. And so, following our reasoning, the next step is how to develop the skills and competences required to suit this change of model. This is where we enter the field of education and learning. It is not excessive to say that the $21^{\text {st }}$ Century society will be a Learning Intensive Society in which educational models of formal education will undergo a profound transformation and life-long learning will become a regular activity of all professionals, who will find it to be the only reasonable way to permanently update the skills and competences that the socioeconomic situation will generate continuously.

Together with the Learning Intensive Society concept another term has gained popularity after it appeared in a report published in 2006 by the Institute for Prospective Technological Studies, as a way to embrace a different view of future learning (Punie and Cabrero, 2006). This term is Learning Spaces, which intends to encompass such a multifaceted reality as learning by including both tangible and non tangible aspects, therefore separating itself from the idea that learning spaces can only refer to physical locations (classrooms, research laboratories, one's own home, etc). To the contrary, it shows that ideas, persons and objects are mobile and they come together in 24/7 asynchronous contexts.

It is not unreasonable to say that we are entering a setting in which the limits between educational institutions and people's homes, between formal, non-formal and informal learning and between teachers and students are all becoming blurred. One of the reasons that leads us to this hypothesis is the emergence of combined educational environments, in which the role of transmitting knowledge, that has traditionally been more or less monopolized by educational institutions, is gradually being taken over by other agents, not necessarily educational ones, that exist in the web and whose most relevant example is Web 2.0.

A possible consequence of the changes we have listed above could be a hypothetical scenario in which children's schooling would no longer be compulsory in 2020, whereas different communities would decide how to manage aspects concerning children's education and safety. The challenge for each Ministry of Education would then be how to handle the shift from large educational institutions, the school-factory type with a great number of students and homogeneous teachinglearning methods for them all, allocating resources for the take over of new unique 
organizations which would offer distinct teaching-learning services to a much more reduced number of students. In such circumstances each Ministry of Education should also provide for mechanisms that can guarantee the development of evaluation, quality and accreditation systems that assure with utmost clarity that results are being achieved according to regional, national o supranational standards.

\section{Significance of Web n.0 on the 2020 Educational Horizon}

The uprise of combined learning environments, such as Learning 2.0, can be seen as a sign of the rupture of the highly consolidated notion as to the role institutions play in education and training, which could give way to a new educational culture. At present Web 2.0 tools have changed the rules of the game in the environment of Internet, communication and education. But we cannot exclude that this new environment may encourage novel learning and communication philosophies in Internet, so we will surely witness the rise and development of Web 3.0, 4.0 and so forth. All of which will be accompanied by related developments such as Learning 3.0, 4.0, etc. Therefore, although on the 2020 horizon we will probably be referring to Web n.0, right now we will concentrate on Web 2.0 and its present implications in order to explain the challenges the educational sector will have to face.

Learning 2.0 is a philosophy based on a Web 2.0 platform, as opposed to closed virtual learning environments and content management systems. Learning 2.0 favours creating and expanding interest groups and communities of practice that can remain active even after the lecture/course/module is over (Ala-Mutka et al., 2008), thus promoting collaboration between peers. The key to the development of this collaboration can be found in the way the new available tools on which this teachinglearning philosophy is based motivate and hook people. The student takes control of the learning speed, structure and contents thanks to diverse audiovisual resources.

Probably one of the main challenges that Web 2.0 will bring regarding pedagogic and organizational innovation is the fact that learning seems to be surpassing the limits of formal education and traditional schooling systems. This means questioning matters such as: (a) what kind of learning can be found beyond the limits of formal education; (b) what role do educational methods play in today's society; and (c) which educational methods can best provide the skills and competences that our socio-economic environment is demanding (there is a growing demand to alter these methods towards more active ones that concentrate on the social construction of knowledge, instead of the more passive type, including traditional instructionist theories).

\section{Challenges for ITEM in the 2020 Scenario}

If we take a look at current educational institutions we can see that investment in Information Technology (IT) in primary, secondary and higher education is still at an initial stage (Miller et al., 2008). Although there is abundant empirical evidence to show that investment in IT has had a positive impact, it is also widely agreed that it has not been developed to its full potential. This is because little attention has 
been given to the pedagogic opportunities it offers, instead of which it has basically been used to give support to teaching structures and methods of the past and as a vehicle to improve communication while using traditional pedagogic and didactic resources. In this sense, IT investment seems to have had a greater impact on administrative services, such as admissions, registry, payment of fees, purchases, staff and timetable management, etc, rather than on the foundations of teaching and learning (Miller et al., 2008; Balanskat et al., 2006).

This leads us to a matter of utmost importance: what role shall Information Technology for Educational Management (ITEM) play on the 2020 horizon? As we have mentioned above, there is a risk that is may be used exclusively for administrative support purposes and, though this is a fundamental task which must be carried out as efficiently as possible, ITEM should not be reduced to this merely operative function. A shared strategic vision must be found to give ITEM long term meaning of added value.

At this point we should decide what part of the IT-EM equation should centre our efforts and in what way. In other words, should we concentrate on what technology (IT) can bring to education on the 2020 horizon, especially emerging technology that we have called Web n.0, or, on the other hand, should we focus on the educational side of this equation (EM). Our aim is to try to achieve a reasonable balance between both IT and EM in order to offer a unified vision of ITEM, but we must keep in mind certain aspects that will possibly set the pace of its development.

Firstly we must consider a basically technical matter regarding how to guarantee universal access to IT, the bandwidth, the use of open-software and author's rights in respect of the contents. Certainly, technological infrastructure evolves along its own channels. This way, even though in developed countries cable based nets have become well established, connectivity based on mobile technology is growing strong and is the main way of connecting to the Internet in developing countries. Universal access to the web brings about certain uniformity in educational management practices, thanks to an increased knowledge and replication of successful experiences in points of the globe that are geographically far apart. In such a context, the search for solutions other than owner software will bring an upsurge and prevalence of tools based on open-source software, which, in turn, will allow technological resources to become more democratically available to people all over the world. Lastly, within this democratising trend we will very likely reach a stage in which not only tools will be freely available, but also contents and, therefore, creative commons type formulas will certainly be more thoroughly developed.

Secondly, concerning educational management, it is necessary to support the design and development of new educational applications and also to actively involve teachers in the process of defining requirements and adopting iterative design approaches. In general terms, one of the main aspects of management is generating leadership that will encourage people to work towards corporate goals. In a similar manner, educational management must efficiently guide changes that are already ocurring in the world of education and will continue to do so in coming years. A first class challenge in educational management concerns the fact that there are educators of different age groups and propensity profiles towards the use of information technology and, therefore, towards a cultural change in teaching methods and 
organization. It will be necessary to establish methods that are recognized as effective to assist this change of attitude and in working ways. In this sense, the existence of communities of practice, as well as making known their results could be powerful ways of involving teachers in the new system.

Finally, if the trends we have mentioned are leading us towards new educational environments which may even place in doubt the figure of schools and other educational institutions, then we must consider how to manage them from the point of view of the institution itself, municipalities, regions and, lastly, countries. Undoubtedly this implies the appearance of new standards and models with which to manage educational activity. On the other hand, due to the foreseeable dispersal of educational institutions and the teaching methods that will be in use, Information Technology's position will be more important than ever in such circumstances, as it will be the only link to coordinate and run this immense network. So the convergence of IT and educational management (EM) reaches its high point because the means to achieve quality, coherence and interchangeability among future education systems must be based on technology, that is, IT as the facilitating element. In such a context, accreditation systems implemented by national and international agencies will be especially relevant. These systems must guarantee that students have, in effect, acquired certain competences, the consistency of goals achieved in different teaching communities and also the transnational validity of resulting certificates.

\section{Conclusions}

Present educational models reflect the needs of an industrial society, whose paradigm is progressively giving way to a knowledge based society. Learning in a knowledge based society has different requirements and, therefore, it is still to be defined. As well as this, constant changes in Information Technologies also alter what we consider to be the vision and mission of educational institutions. We don't yet know which will be the prevailing educational philosophy on the 2020 horizon, nor do we know what version of the Web will be supporting it. But we have little doubts that we do not know for sure what the educational model will be like then, even though it will retain many of the characteristics that inspire the present one.

We must be ready for what looks like a possible trend, that is, schools and teachers will lose importance in favour of more flexible structures managed according to business models, which will be much more competitive and transparent due to the inevitable need to gain students as clients. In such a context a new design of ITEM must be developed.

On the 2020 horizon, in order to reach its full development, the ITEM field must support technological infrastructure related standards, as well as the measures to promote cultural change associated to the new educational model. It must also be the means to ensure homogeneity in a highly fragmented environment in which customized education based on knowledge will break with the postindustrial educational model, according to which we have carried out learning processes for decades. 


\section{References}

1. Ala-Mutka, K., Bacigalupo, M., Kluzer, S., Pascu, C., Punie, Y., Redecker, C.: Learning 2.0: The Impact of Web 2.0 Innovation on Education and Training in Europe. Report on a validation and policy options workshop organized by the Institute for Prospective Technological Studies (2008)

2. ANECA: Agencia Nacional de Evaluación de la Calidad y Acreditación: El Profesional Flexible en la Sociedad del Conocimiento: Nuevas Exigencias en la Educación Superior en Europa' (REFLEX) en España (2008)

3. Balanskat, A., Blamire, R., Kefalla, S.: The Impact of ICT on Education -a Review of Existing Studies Analysing the Impact of ICT. EUN European Schoolnet (2006), http://insight.eun.org/shared/data/pdf/impact_study.pdf

4. Breshanan, T.F., Brynjolffson, E., Lorin, M.H.: Information Technology, Workplace Organization and the Demand for Skilled Labour: Firm Level Evidence. The Quarterly Journal of Economics, 340-376 (2002)

5. European Commission $\{\operatorname{COM}(2008) 868\}$ : New Skills for New Jobs: Anticipating and Matching Labour Market and Skill Needs. Communication from the Commission to the European Parliament, the Council, the European Economic and Social Committee and the Committee of the Regions (2008)

6. Machin, S., Van Reenen, J.: Changes in Wage Inequality. Special Paper No 18. Center for Economic Performance (2007)

7. Miller, R., Shapiro, H., Hilding-Hamann, K.E.: School's Over: Learning Spaces in Europe in 2020. European Commission (2008)

8. Punie, Y., Cabrero, M.: The Future of ICT and Learning in the Knowledge Society. Report on a Joint DG JRC/IPTS-DG EAC Workshop held in Seville 21-22 October 2005, DG JRCIPTS, European Communities, March 2006, EUR 22218 EN (2006)

9. UNEP: United Nations Environment Programme: Green Jobs: Towards Decent Work in a Sustainable; Low-Carbon World. Report commissioned and funded by UNEP (2008) 